\title{
La experiencia, la mirada y la investigación: Una lectura al quehacer del Maestro desde la Práctica Pedagógica.
}

\section{The experience, the look and the research: A reading to the teacher's task from the Pedagogical Practicum.}

\section{Por: Osorio González Angélica ${ }^{1}$; Camacho Laura, Cristancho Cindy Paola, Morales Maritza, Rada Claudia Rocío, Oliveros Viviana, Rodríguez Eva María, Rodríguez Magda $^{2}$}

El presente escrito resulta de la construcción colectiva del grupo de práctica pedagógica del segundo semestre de 2008 en el marco de la Línea Trayectos y Aconteceres estudios del ser y el quehacer del maestro desde la pedagogía, texto que ha sido elaborado a propósito de las discusiones realizadas al interior del seminario, las vivencias y reflexiones de las estudiantes de práctica I y II que permiten pensar, problematizar, analizar y proponer los diferentes elementos que se conjugan en la práctica de los maestros. Es así una mirada que se hace desde la interioridad al afuera y al adentro de la práctica o de las prácticas, una lectura desde la investigación, desde la sensibilidad y desde la pedagogía.

\section{Ver y Visibilizar: Una posibilidad para el empoderamiento de la práctica del maestro}

¿Cuándo y cómo nos hacemos maestros?, esta es quizás una de las tantas preguntas que a lo largo de nuestra práctica como maestros vamos resolviendo no sólo con enunciados que por momentos parecieran respuestas sino con nuevas preguntas que emergen en las múltiples vivencias que hacen parte de nuestro ejercicio como maestros. Ver y vivir la escuela, ver y vivir la enseñanza, ver y vivir la universidad, vernos y ver a los otros como sujetos de la educación, son tal vez, algunos elementos que nos van configurando como maestros. Aunque habría que aclarar que "ver" en este caso se relaciona no solo con una percepción resultante de los sentidos sino principalmente, con la forma en la que decidimos leer las imágenes, los discursos y las prácticas que se materializan tanto en la escuela que pareciera ser el escenario por excelencia de la práctica de los maestros como en la universidad el aparente lugar por excelencia de la academia; se trata así de visiblizar y por tanto de preguntarse por lo visible, de mirar cuáles son sus precedencias y sus efectos al interior de nuestras prácticas. De este modo, se conjugan reflexiones, sentimientos, conflictos y otras situaciones en el transcurrir de la práctica; en la que el diálogo, el debate y el análisis tanto de las vivencias como de la "teoría educativa y pedagógica" se constituyen en elementos que enriquecen la mirada que desde la práctica se hace al ejercicio de maestro y es tal vez en el ejercicio de la problematización de lo que se ve, en la

${ }^{1}$ Coordinadora de Práctica Pedagógica, Línea de Investigación Trayectos y Aconteceres estudios del Ser y el Quehacer del Maestro desde la Pedagogía.

2 Maestras en Formación, Línea de Investigación Trayectos y Aconteceres estudios del Ser y el Quehacer del maestro desde la Pedagogía. 
aparición de la inquietud y del conflicto donde emerge la posibilidad de pensar de otro modo y construir de manera distinta el quehacer del maestro, pues pareciera que el quehacer del maestro desde la pedagogía, no es simplemente ejecutar acciones que se encuentran enmarcadas dentro de un contexto, no se trata de reproducir modos de enseñar, de aplicar una estrategia eficaz sino de crear, de analizar, de preguntarse por el sentido de lo pedagógico, por la enseñanza de las ciencias y de la biología, por los sujetos que comparten escenarios con los maestros, por el país en el que enseñamos y por las alternativas que pueden construirse tanto en el enseñar como en la enseñanza.

Pareciera entonces, que es la problematización, la que permitiera visibilizar y en este proceso que podría llamarse investigativo, acontece el surgimiento de ideas y de apuestas apropósito del maestro, del saber y del poder; entonces sería la investigación en este sentido, la que posibilita mirar, construir y resignificar el quehacer del maestro desde la pedagogía, así asumiríamos la investigación como un acto de pensamiento, retomando

Siendo asimilable al propio acto de pensar, la actividad de investigación se encuentra, así, sumergida en una segunda figura a revertir: el pensamiento, en cualquier área que se realice, no es de ningún modo una opinión (ni una mera reflexión), sino una invención, sea de conceptos, de sensaciones y de funciones (Costa de Almeida y Novais, 2008)

Asumiríamos entonces el quehacer del maestro como un ejercicio intelectual que desde la investigación permite pensar el mundo, el yo y el otro y construir posturas frente a diferentes modos de ver, de construir saber, de problematizar y de proponer respuestas.

Los diferentes trayectos realizados durante la práctica han permitido analizar cómo en la historia de esta sociedad, paradójicamente a la vez que el maestro ha sido exaltado en la idea que de él se persigue, ha terminado casi oculto y desconocido en su existencia en la cotidianidad de su práctica. Por esto al buscar dar razón de lo que el maestro es, se ingresa en un mundo claustrado de simbolismos y significados donde toman parte el entorno social en el que se desenvuelve, como también las múltiples instancias a que está expuesto, su propia historia personal y la cultura acumulada, que en diferentes periodos ha ido creando un rol que desconoce continuamente a un docente como un sujeto creador y transformador de su propia práctica.

Si todo el que ha tenido que ver algo con educación, se ha preguntado siempre ¿Qué es lo que hace el maestro?, hoy por primera vez en la historia de nuestra práctica pedagógica la respuesta ha dejado de ser evidente clara y distinta. Pero por primera vez también, hoy se abre la posibilidad de que esa pregunta vuelva a las propias manos, y no solo a las de los expertos que se las respondieron siempre de antemano y sin ninguna duda (Saldarriaga, 2003 p.303).

La práctica pedagógica, permite ver un entramado de situaciones que dejan apreciar el encuentro y desencuentro cotidiano entre el maestro y el estudiante, entre el ideal y la realidad, entre el presente y el futuro; el espacio cotidiano de negociación de conocimientos, valores, normas etc.; en ese sentido para dar cuenta de la actividad docente no basta con estudiar los contenidos, y no es suficiente abordar la relación enseñanza-aprendizaje. Por tanto es indispensable comenzar a pensar las relaciones sociales, ya que la educación, y en particular la docencia, están determinadas por la historia, por un contexto socioeconómico y por políticas educativas planteadas en un momento histórico determinado, un espacio de múltiples intervenciones por parte del otro. 
Expresar la complejidad del quehacer del maestro, requiere introducirse en la vida cotidiana de las escuelas, en el espacio donde dicha labor adquiere diversas formas, múltiples particularidades y voces concretas. El quehacer docente no es un trabajo lineal ni fácil, está lleno de ambigüedades, imágenes e historias contradictorias se trata de un espacio de múltiples fuerzas, de condiciones, y de alianzas cambiantes dentro del sistema escolar. En ese sentido, al estar enmarcada la práctica del maestro en un espacio social, el maestro se encuentra incluido en una red de relaciones que lo ubican en un lugar con ciertas exigencias, y lo sitúan en cierta relación de poder con el otro. La práctica del maestro permite ver, una lucha permanente por la apropiación del campo de trabajo y por la participación efectiva en las decisiones. En una búsqueda permanente por ser reconocido como generador y creador de su propia labor.

El maestro es visto por momentos como el constructor constante de una práctica que pretende ser diferente y eficiente, pero en otros como un moldeador del salón de clases como un intermediario de los procesos del aula. Actividades y modos de asumirse que terminan siendo realizadas muchas veces de manera consciente, y otras tantas inconscientemente. Cada experiencia termina siendo diferente, están compuestas por pequeñas realidades particulares, realidades que se van construyendo cotidianamente en el transcurrir de la práctica y que por tanto son cambiantes y se concentran en la historia y en la sociedad.

Si se piensa desde la perspectiva que ve la docencia como una actividad, lineal y simple y a la que se le suma el control que ejercen la sociedad y la institución sobre el maestro, se tiende a desconocer al maestro como sujeto activo, y se deja un margen limitado para el desarrollo de iniciativas que vayan más allá del salón de clases. Hoy los cambios sociales y políticos, se propagan directamente en las personas que tienen como oficio el quehacer educativo, concretamente en los docentes, cuyo desempeño profesional se torna día a día en un quehacer más complejo y demandante de nuevos conocimientos y habilidades, para los cuales muchas veces no han sido formados, actividades que son objeto de control institucional.

El maestro es cada vez mas objeto de una sistemática observación hasta el punto que ni una sola de sus actividades dentro o fueras del salón de clase o de la escuela dejan de ser observados o quedan por fuera del control y regulación de las normas (Martínez Boom, p.367).

En ese sentido, los profesores, en múltiples ocasiones hacen frente a la problemática diaria de manera empírica, solucionando en el plazo inmediato algunas de las dificultades que se le presentan, sin que por ello queden resueltas del todo, "sometido" a miles de encrucijadas que no permiten ver la solución. Ante esto se plantea generalmente el reto de establecer proyectos de formación de docentes. En muchos de estos programas de formación se piensa a los maestros como seres abstractos, a los que basta distribuir cursos de capacitación o simplemente dar incentivos para mantener su "autosuperación" y el mejor desempeño de su actividad olvidando quizás sus verdaderos intereses y características particulares, así como las condiciones concretas en las que desempeñan su trabajo, de esta manera es posible que no impacten ni a los maestros ni a la comunidad. Por tanto se hace necesario intentar generar soluciones a los problemas que el trabajo mismo plantea, y sobre todo, en las circunstancias específicas en las que se desarrollan. Este proceso también hace necesaria la reflexión continua de saberes integrados a la práctica cotidiana, donde hablar y pensarse al maestro nos lleve a una transformación permanente, como una manera indispensable para entender a la formación de docentes, desde una dimensión compleja y cambiante. 
La practica pedagógica se constituye así en una practica de saber en donde se producen reflexiones sobre diversos objetos y de este modo las relaciones entre los elementos que la conforman se recomponen permanentemente superando la imagen de algo estático y perfectamente definido (Martínez Boom, 2008).

Hablar del maestro, pone sobre la mesa la importancia de que éste resignifique y transforme su práctica, que la re-cree, que se convierta en sujeto activo. La situación actual requieren que los maestros traspasen los muros que aprisionan la práctica, haciendo frente a la historia que pesa sobre dicho quehacer, para que de esta manera pueda reconocerse como sujeto de su propia historia. Parte crucial en el proceso de recuperación de la práctica de los maestros esta en es problematizar permanentemente su actuación, su relación con el otro, para que de esta manera se pueda salir de la soledad en la que muchas veces se ha ubicado su trabajo, para coincidir con otros colegas, intercambiando experiencias, investigando y reflexionando su profesión. La educación está viva, cambia, se construye y se replantea. Pero para ello se requiere de un sujeto: el maestro, que se represente a sí mismo como transformador activo, un maestro que se empodere de su práctica (aunque a veces tristemente no lo realice) y que sea un ser consciente de su compromiso y de su labor, porque de otra manera, se quedará sirviendo a los centros de poder, donde es un vil instrumento de un sistema que roba los anhelos y las ilusiones. Se trata de que no seamos como menciona Saldarriaga (2003) "legión de mediocres" de que hablaba el padre Ruiz Amado, compuesta esta vez por el ejercicio de maestros "privatizados" que no tendrán otra alternativa que trabajar como aquel primer pedagogo en Grecia, ¡ah, malhadado profeta Serres!, esclavos de sus patrones!" (p.304).

\section{II. ¿Maestro o Practicante?: Una reflexión desde el ejercicio de práctica.}

Muchas veces, escuchamos acerca de la práctica un sin número de cuestionamientos frente a como ésta interviene o debe intervenir en la investigación y en la formación del maestro, sobre cómo debe impactar la institución en la que se lleva a acabo, pero, ¿es la práctica sólo el resultado de la intervención en una institución?, ¿es un espacio académico?, éstos y otros cuestionamientos nos permiten reflexionar sobre los discursos que atraviesan esta experiencia, este espacio académico que presenta tanta importancia en las facultades de educación. Es así como en muchas ocasiones se asocia el maestro con aquel que diseña un sinnúmero de actividades o propuestas de aprendizaje para los estudiantes, y a un practicante como a aquel que va a ser el colaborador en esa práctica de enseñar, que va a llegar con ideas nuevas, innovadoras, que va a ser el apoyo en el manejo del grupo y que aliviará el trabajo del maestro. En realidad no está mal pensar eso, lo que se hace en la clase es parte del quehacer maestro, lo conflictivo está en creer que es lo único. Para quien está en práctica no sólo existen los estudiantes y los maestros, también están unos administrativos, una historia particular de la institución, unas formas de enseñar, de gestionar, de interrelacionarse no sólo entre sujetos sino en el espacio físico.

La práctica pedagógica no es sólo ir a un colegio, hacer una clase o llamar la lista, si no produce reflexión y movilización sería darle a la pedagogía un sentido mecánico, procedimental, sería dejar de ser maestro y vivir en función de otros perdiendo de vista nuestro quehacer, el sentido de nuestra práctica, nuestro ejercicio intelectual. Si nos movemos en un contexto que no conocemos y no analizamos, seguramente seremos y haremos lo que digan quienes sí lo entienden, y entonces nuestro criterio es el de ellos, y el criterio de los estudiantes será el nuestro, y así una 
tecnología moral circulará, se propagará y se insertará en los individuos anónimamente, entonces, ¿la crítica dónde queda?

No es fácil asumir una posición crítica y movilizadora de nuestro oficio, quizá la formación académica, la experiencia en lo escolar como maestro y como estudiante construyen múltiples formas de interpretar e intencionar lo que hacemos, cada uno en su individualidad, cada uno en su contexto, cada uno en su mundo. ¿Qué tan contraproducente puede ser ello? ¿Tanto para el maestro, para la institución y para los estudiantes? ¿A quién comunicarle nuestras vivencias en lo profesional? Pienso por ejemplo que como practicante un lugar de desahogo, de creación de ideas, de descubrimiento es el seminario de práctica que con su dinámica de lectura, de debate, con la participación de sujetos con distintos roles tanto maestros de colegio, de universidad y practicantes abren perspectivas y sentidos. ¿Los maestros encuentran esos espacios?, ¿los necesitan?, ¿los buscan?

Parte de nuestra biología es ser sociales, una estrategia adaptativa que posibilita el éxito, una frase tan vernácula como "dos piensan más que uno" es reflejo de ello. El quehacer del maestro se construye en colectivo, no sólo desde los sujetos físicos sino también desde aquellos lejanos que han escrito sobre nuestro oficio. Las reuniones, las jornadas pedagógicas, las charlas informales, los conversatorios son espacios que permiten entrar en contacto con otros, que desde su individualidad construyen la nuestra, con sus preguntas, sus inquietudes, los sabores y sinsabores de su quehacer, al respecto cabe mencionar la importancia de las redes

Redes, entendidas como conexiones, intercambios, creación de distintas formas de encuentro donde se privilegie la circulación de los saberes y de las prácticas de los maestros(...)en las que no se instalen conexiones verticales frente a una saber acabado y dogmático; sino más bien experimentaciones, búsquedas, problematizaciones posibilitan "renovar la imagen del maestro en el sentido que se piense a sí mismo (...) que establezca nuevas conexiones, someta a debate y problematice su saber, que genere experimentaciones que le permitan articular nuevas formas del pensamiento (Martínez Boom y Unda, 1995).

Sin embargo y a pesar que en la actualidad se hace más frecuente la idea de reflexionar sobre la práctica y sus actores, siempre quedan aspectos que se diluyen tras las rutinas y se camuflan detrás de nuestra lucha de intentar entender los comportamientos y procederes de las prácticas de los alumnos y los maestros; la pregunta por cómo se configura la institución escolar, la gestión educativa, entre otros se entrecruza con las inquietudes por el deber ser de la enseñanza de la biología, sus sujeciones y posibilidades; aspectos que al parecer no tienen que ver únicamente con la racionalidad que los sustenta sino con la emocionalidad de los sujetos que viven la realidad educativa, emocionalidad que toca los sentimientos, comportamientos y roles del maestro en formación o practicante, durante la práctica pedagógica.

Y no es de más, si analizamos estos aspectos, podríamos darnos cuenta que la mayoría de los practicantes, cuando llegan a este punto de su formación, se enfrentan a una serie de sentimientos y conflictos que ponen en tela de juicio su formación frente a lo pedagógico y disciplinar, o que generan dudas con respecto al rol o papel que cumple dentro del aula. Podría decirse esto porque cuando el maestro en formación llega a la institución o para ser más precisos al aula en donde "realizará la práctica", encuentra en ella una dinámica ya definida, donde subyacen relaciones de poder entre el maestro titular que tiene un "estatus" dentro del aula, y el alumno el cual de cierta forma ejerce cierto poder en ella, confinándolo a un rol intermedio, en 
donde por una parte es visto como maestro y por otro como un estudiante que está aprendiendo de la realidad del maestro; y es ahí donde surge la pregunta por el lugar que debe ocupar el maestro en formación en su ejercicio de práctica; lugar que pasa por la reflexión y que muestra que su papel posiblemente va más allá de la simple observación externa de una "realidad" o de un ejercicio de implementación didáctica.

Por otra parte, la realidad en la escuela y de los sujetos que están inmersos en ella, sin duda es y será un factor desequilibrante para el maestro en formación, ya que posibilita enriquecer y resignificar lo que se ha aprendido durante los años de formación, donde los esquemas y las técnicas adquiridas toman una nueva connotación dentro de la realidad del practicante y su forma de proceder; de la misma forma aparece el "enfrentamiento" con la disciplina y la vigilancia, que de cierta forma se configura dentro de las funciones del maestro y que "deben ser" asumidas por el practicante por más resistencia que oponga, sin embargo surgen nuevamente las preguntas, por las historia de estas prácticas, por sus efectos, por la necesidad aparente de su permanencia y por la posibilidad para transformarlas. No hay que dudar que para el maestro en formación, la práctica se configura como un medio para legitimarse como profesional, que le permite mirar su proceso, pensarlo y analizarlo; a la vez preguntarse por infinidad de situaciones (la escuela, los saberes, los sujetos), así como enriquecer, valorar y cuestionar el conocimiento que día a día es puesto a prueba; donde emergen las preguntas por las procedencias, los sentidos y los sujetos. Es de esta forma como la práctica pedagógica se convierte en una experiencia que incita reflexionar el ejercicio y las implicaciones de ser maestro. Es un ejercicio que permite formarse para la responsabilidad que requiere asumir el ejercicio de la enseñanza.

Por esto, otros han escrito y han pensado la pedagogía como posibilidad de movilización, es decir, la lectura es un factor clave en nuestra continua construcción, Martínez Boom, Olga Zuluaga, Michel Foucault, Christian Laval y Javier Sáenz, sólo por nombrar algunos, quizá nos liberan "el alma" cuando nos permiten desenmarañar nuestra profesión, nos construyen la posibilidad de ser críticos e intelectuales.

Estos son los Trayectos que nos permiten visibilizar las redes de las que hace parte el maestro: la Biología, la Pedagogía; y en ellas su subjetividad, la experiencia, los otros, el contexto escolar, social, nacional, y que por tanto posibilitan en su conjugación la configuración de una práctica pedagógica.

\section{La Práctica Pedagógica: Experiencia y Movilización de Pensamiento}

Sin duda alguna durante los primeros seis semestres de la formación como Licenciados en Biología nos hemos acercado de diferentes maneras al contexto educativo, no obstante es en el denominado ciclo de profundización y, particularmente en la "práctica pedagógica" que se hace explícito un momento para este "reencuentro", un reencuentro que involucra desde el observar hasta el sentir, el vivenciar, el experimentar, el responder (o procurar hacerlo), el proyectar o el indagar aquel espacio físico, pero fundamentalmente ámbito de sujetos, relaciones, discursos y prácticas conocido como escuela. El titulo dado oficialmente al acercamiento que hacen los maestros en formación a la escuela es práctica docente el cual es un espacio institucionalizado por la Universidad que busca entre otras, formular proyectos que respondan a las diversas problemáticas que se observan en las instituciones educativas; sin embargo en el caso de la 
Licenciatura en Biología ésta es denominada práctica pedagógica y didáctica especifica donde se busca por medio de las diferentes Líneas de investigación generar reflexiones en torno a la enseñanza de la biología permitiéndoles a los estudiantes pensarse a sí mismos y a su labor .

Vistas de la anterior forma pareciera que la práctica tiene la misma dirección, sin embargo las palabras cambian totalmente el sentido de las acciones propuestas para las mismas; la palabra docente connota a un sujeto que transmite información, un sujeto ubicado dentro una jerarquía social, académica, reconocido tal vez por el domino de la disciplina que enseña; en cambio la palabra maestro tiene una trayectoria histórica y cultural, esto no quiere decir que la anterior no la tenga, pero la segunda define a una persona dedicada en palabras de Saldarriaga (2003) al oficio de enseñar que por tanto tiene como herramienta fundamental un método; y por tanto el maestro esta arraigado al saber a su formación social y cultural, participa activamente en todos estos campos los cuales generan experiencias que reflexionadas crean saberes pedagógicos. Por lo anterior lo que diferencia dichas prácticas y los sujetos que participan en ella es el resultado de la forma institucional y de la adecuación de los saberes, más no es una distinción que se derive de la naturaleza de la pedagogía, en últimas de la experiencia.

Dicha experiencia de ninguna manera se ve limitada por los muros de la institución escolar, al contrario, al tener como característica principal la exploración y la movilización del pensamiento por parte de los sujetos (los maestros en formación y en ejercicio), haciendo que desborde los lugares, las instituciones, permite que se establezca una relación entre la escuela y la universidad (siendo ésta un espacio privilegiado para la discusión y el debate con pares académicos, además es un espacio de investigación y producción de conocimiento pedagógico por excelencia), un diálogo que debería ser permanente ya que posibilita enriquecer las lecturas de la escuela y todo lo que ésta implica, en definitiva genera perspectivas diferentes a las personas que están involucradas en ella (en la práctica pedagógica) a propósito de su lugar como maestros, como "sujetos del saber pedagógico", como "personas dedicadas al oficio de enseñar", viabiliza otras miradas relacionadas con la enseñanza y con los conocimientos y saberes a enseñar, para el caso la biología.

Es difícil creer que en este escenario no haya cabida para la reflexión del significado mismo de la práctica pedagógica desde la posición de maestros en formación y como no lejanos maestros en ejercicio, por lo que es verosímil asumirla como una noción que se construye desde la escuela y la universidad, particularmente con la Línea de Investigación Trayectos y Aconteceres, a partir de las miradas, reflexiones y discusiones que en estos escenarios se posibilitan.

En este sentido, podríamos hacer referencia a diferentes dimensiones de la práctica pedagógica, aclarando que no por ello se excluyen, al contrario se cruzan y complementan, haciendo que el quehacer del maestro sea un oficio interdimensional.

En primer lugar, haciendo referencia a algo ya anotado en líneas anteriores, la práctica pedagógica como un escenario que no se limita a la escuela, involucrando espacios como la universidad, la investigación, el debate y la discusión con otros maestros, es decir como un lugar de y para la problematización de cuestiones que atraviesan al maestro constantemente. El libre intercambio de pensamientos, saberes y prácticas propias de la pedagogía como saber genera que la práctica pedagógica desde los ámbitos que tiene lugar y que podríamos denominar dimensiones, sea una experiencia de carácter constitutivo pues incita a pensar de otras formas, abre las perspectivas para ver, sentir y escuchar de manera diferente, y en este sentido puede llegar a 
considerarse un espacio de conflicto y de crisis, siendo esta última noción de gran significado desde los planteamientos de Martínez Boom (2008) al guardar en su interior la potencia de la reacción o la posibilidad de cambio, entonces la práctica pedagógica se convierte en un territorio de transformaciones (en el amplio sentido de la palabra) relacionadas no sólo con el maestro sino también con la enseñanza, la educación, los estudiantes, los saberes de enseñanza, la pedagogía... en otras palabras pensarla como materialización de las reflexiones que también de ella surgen. Al respecto, sería pertinente mencionar la noción que utiliza Carlos Noguera (1991)

"gesto pedagógico", ya que da cuenta del momento de gestación de una nueva manera de ser del pensamiento, en donde el "gesto" implica una categoría, entendida como una manera de proceder en el discurso, y una actitud, como una forma de estar en el mundo, una nueva actitud frente a las prácticas pedagógicas" (Noguera, 1991, p.26).

En este sentido, podríamos considerar que las reflexiones que tienen lugar en la práctica pedagógica, producen más interrogantes que "soluciones totales" permitiendo que emerja una serie de relaciones que confluirán en patrones fáciles de visualizar; estos patrones pueden convertirse en una fuente de investigación del quehacer del maestro, convirtiéndolo en un participante activo de la pedagogía, rescatando su papel en la escuela y ante la sociedad, evitando convertirse en un instrumento de los modelos educativos de moda, en palabras de Zuluaga, (1999) en un instrumento pedagógico. En otras palabras, esa movilización de pensamiento, de experiencia, de saber, no sólo es motivo de satisfacción personal para el maestro o de enriquecimiento de su quehacer en la escuela, pues en realidad se trata de un aporte al saber pedagógico en tanto saber ${ }^{3}$ del maestro por excelencia. Las reflexiones del maestro (bien sea en ejercicio o en formación) se suelen situar en la enseñanza, la escuela, el niño, el conocimiento y la instrucción, objetos del saber pedagógico, que el maestro al estar relacionado con estos e inmerso en el saber pedagógico algunas veces no los hace objetos de cuestionamiendo y pensamiento.

Retomando la práctica pedagógica desde la formación de maestros, pero no desligado de lo mencionado, el intercambio libre que se posibilita está entre maestros en formación y maestros en ejercicio puede generar nuevos conocimientos que van más allá de novedosas actividades didácticas propias de la disciplina y de cómo enseñarla para que los estudiantes la aprendan, lo que Zuluaga, (1999) denominaría un simulacro de práctica, que desvía el saber pedagógico, bloqueando la articulación de conceptos y experiencias en la formación docente.

La creación durante la práctica de objetivos comunes ente los sujetos practicante- maestro hacen que la enseñanza no se reduzca como ya se mencionó a la acción instrumental impidiendo el hilo conductor de la misma, estos objetivos nos permitirán analizar la cotidianidad con otros lentes: unos nuevos que están dispuestos a sorprenderse y otros llenos de experiencia, que por medio de la reflexión y problematización crearan alternativas en el contexto educativo que algunas veces se presenta al maestro en ejercicio como monótono. Por lo anterior, la práctica pedagógica constituye un espacio de construcción social, política y ética de nuestro quehacer como futuros maestros, ya que durante ésta se visibilizan los juicios, desconciertos, incertidumbres, miedos, fortalezas, gustos, entre muchas más características particulares a cada uno como maestros en formación, así como las situaciones del maestro colombiano en general, de la educación, de la pedagogía y la

${ }^{3}$ El saber como lo expone Martínez Boom es definido como una categoría que agrupa diferentes y diversos discursos, conceptos, nociones, conocimientos, en fin objetos de saber formados de manera regular por una práctica discursiva, estos objetos de saber son los que dan la particularidad al saber que constituyen. 
enseñanza, elementos que participan en una constante reconstrucción del maestro que queremos ser, una labor que posiblemente nunca termine.

Estas construcciones (valga decirlo colectivas), permiten asumir de otras maneras al maestro y a su quehacer, por ejemplo como un sujeto de sí mismo, que a partir de los procedimientos que hace sobre su propio cuerpo, sobre sus pensamientos, sentimientos y actos se construye de manera activa, logrando orientar sus acciones a lo que verdaderamente quiere y desea, no porque se le exija de manera absoluta desde el exterior.

También evita caer en los reduccionismos de que es objeto el maestro y su oficio al enfatizarse frecuentemente en la concepción instrumental del método de enseñanza, esta situación prepondera la utilización y aplicación de unos pasos (exitosos en sí mismos) y omite la enseñanza como acto complejo que más que aplicar un secuencia determinada de etapas permite la circulación y dialogo de diversos saberes, no sólo de aquellos señalados como los conocimientos o la información tendientes a la conformación de habilidades y destrezas cognitivas en los niños y jóvenes, sino también a las distintas manifestaciones de la cultura. Como se mencionó anteriormente, el maestro se piensa y problematiza lo que le rodea y le constituye no sólo desde el contexto de la escuela, que sería una de las dimensiones de su práctica, sino también desde otras como la investigación y la discusión con pares académicos, a partir de estas posibilidades y de las condiciones que el mismo ambiente de la clase y la escuela generan, la enseñanza no está determinada a modo de recetario y no es simple.

Desde esta perspectiva la experiencia antes mencionada es entendida por Foucault (2005) como "la correlación, dentro de una cultura, entre campos de saber y tipos de normatividad y formas de subjetividad" (p.2), con lo cual se asume que ésta tiene unas condiciones históricas unas formas de saber y de noramatividad que en relación con la cultura se materializan en el sujeto. Así mismo, a partir de la práctica como experiencia se generan saberes que sólo emergen al poder encontrase en dicha correlación, con los sujetos, las instituciones y las normas de la escuela, al ver ya a la vez hacer parte de la red de relaciones y de fuerzas que se tejen por medio del intercambio de sentimientos y saberes lo que Foucault (2005) denomina los tres ejes constituyentes: "la formación de saberes que a ella se refieren, los sistemas de poder que regulan la práctica y las formas según las cuales los sujetos pueden y deben reconocerse como sujetos" (p.2); el poder que puede llegar a dominar, persuadir o parecer invisible (en silencio) que en la escuela está marcada por las jerarquías, la evaluación, la competencia y la lógica de la gestión, que afectan a los sujetos que participan en ella.

Estos elementos han sido evidenciados en los trayectos de la práctica de la Línea de investigación Trayectos y Aconteceres, y funcionan como referente para explicar que las prácticas cambian con el tiempo, los sujetos y las instituciones, además de la normatividad que esté vigente, dependiendo de la forma en la que participen los sujetos en las relaciones que se tejen, por ende las experiencias son únicas y tal vez irrepetibles y en este sentido connotan un acontecimiento.

Foucault (2005) menciona que estos cambios, figuras históricas singulares hacen parte de sí mismo, por tanto podríamos decir que la práctica nos permite constituirnos como maestros, esto no quiere decir que fuera de ella no lo seamos más bien es un espacio que nos permite poner a prueba los referentes que se tenían, confrontarnos sobre la responsabilidad que tenemos a nivel social, político y cultural. En este punto, es pertinente reconocer que la práctica del maestro se ha visto envuelta desde hace mucho tiempo por diferentes fuerzas con pretensiones de 
circunscribirla y controlarla a través de dispositivos que, no pocas veces, se ocultan bajo del manto de la instauración de necesidades llegando a ser asimilados como normales por los mismos maestros. Precisamente es en esta situación, que la práctica pedagógica se convierte en una válvula de escape para el maestro, siempre y cuando la misma no se pierda en la monotonía y la normalización. Muestra de ello, es la imposibilidad de estos mecanismos de ocupar todos lo espacios del maestro, pues aunque se le ha querido controlar de muy variadas maneras por ejemplo con leyes, autorizaciones estatales o eclesiásticas, planes de estudio, parceladores, libros de notas o sabanas curriculares, aunque se le ha pretendido legislar, diseñar y controlar el maestro sigue teniendo potestad en tanto sujeto que se piensa, que tiene una posición ética, política y estética ante su ser como maestro y su oficio. Por tanto un modo de resistencia consiste en documentar las experiencias de las prácticas dejando un registro de las figuras históricas singulares que caracterizan un determinado contexto en una época y que pueden dar explicación a las prácticas discursivas que permitirán analizar la formación de saber y poder, en palabras de Foucault la historia que no sería aquella de lo que puede haber de cierto en los conocimientos, sino un análisis de los "juegos de verdad" de los juegos de falso y verdadero como experiencia, es decir como poderse y deberse ser pensado para nuestro caso el papel del maestro desde la práctica.

\section{EL Lugar de la Investigación en la Práctica}

Al interior del departamento de Biología, la investigación ha sido dinámica y cambiante, como lo describen Valbuena, Sierra y Gutierrez (2007) “en un comienzo estaba soportada principalmente en los trabajos de grado de los futuros profesores, y en la actualidad se desarrolla al interior de grupos y líneas de investigación lideradas por formadores de formadores" (p.147). Así mismo, dentro del amplio campo de investigación desarrollado en el DBI es posible encontrar múltiples visiones del ser maestro enmarcadas a partir de diferentes contextos y perspectivas, las cuales se hacen evidentes al interior de las líneas de investigación y se consolidan en la práctica pedagógica. Es así, que la investigación constituye una forma de ser maestro, en tanto le posibilita pensarse y pensar la realidad escolar a partir de una reflexión de su quehacer, de manera que, pedagogía e investigación son inseparables, Ramírez (1998) menciona al respecto que

La investigación es la única manera como la pedagogía puede llegar a convertirse en un proceso educativo humano que tiene que cualificarse permanentemente. Su modo propio de proceder le exige investigar o deja de ser pedagógica para convertirse en un simple acto de reproducción mecánica. Nada más alejado de la esencia de la educación de personas" (Ramírez, 1998, p.163).

De igual forma, la posibilidad de pensar, a lo largo de la práctica pedagógica en un problema investigativo que genere reflexiones en el maestro en formación, es el resultado de acontecimientos históricos que nos han permitido y abierto esta posibilidad.

Durante los últimos once años ha surgido una oportunidad para las Instituciones universitarias en cuanto a establecer y fomentar la construcción de una "cultura de la investigación" en los procesos de formación, para dirigir su accionar a problemas de importancia del entorno a fin de vincular el contexto a ellas. Las Instituciones de Educación Superior se están encontrando con más frecuencia bajo presión por parte de la sociedad que las interroga, para abrirse por el camino de la investigación, aumentando con ello una cultura hacia esta función esencial. Para el desarrollo institucional, esto es fundamental 
porque si se establecen políticas y estrategias hacia ese objetivo, esta oportunidad lleva a posicionar a una Institución en lo regional, nacional e internacional. (Mora, 2008, p.12)

Entonces, cobra sentido la investigación desde el plano institucional, como una función escencial lo que es de algún modo una condición que posibilita abrir caminos desde la investigación a los maestros en formación que hacen parte de las facultades de educación. Lo anterior hace necesario reiterar el compromiso de los maestros al pensarnos como investigadores reflexivos al interior de una realidad escolar particular, donde lo verdaderamente relevante es que se haga pensándonos y pensando nuestro quehacer.

\section{La pedagogía y la didáctica en el quehacer del maestro: Aproximación a una problematización.}

Durante la formación como maestros se pueden encontrar diferentes componentes que buscan dar sustento al quehacer docente (o como maestros diríamos otros) emitiendo algunas luces sobre la complejidad que involucra la práctica del maestro no solo en el aula sino en la sociedad. Se hace este proceso de formación aun mas consistente cuando tenemos la oportunidad de problematizar esas prácticas. Mirar eso que tiene tanta importancia para los profesores, importancia que llama la atención y que no implica que no podamos cuestionar, analizar y decidir también que nos parece apropiado de acuerdo con intereses individuales y colectivos.

Una de las tensiones educativas evidenciadas se da desde dos frentes: la pedagogía y la didáctica, la cual resulta de las observaciones y reflexiones en el desarrollo de la práctica pedagógica; posiblemente se realicen aseveraciones que son efectos de un sentir y de la imagen proyectiva de lo que sería la propia práctica como maestros desde las condiciones que posibilitan ese quehacer.

Aparentemente las preocupaciones de los maestros están dirigidas más a la didáctica que a la pedagogía, y podría decirse que esta relación de "prioridad" en ocasiones no es claramente percibida por parte de los maestros, es decir, al parecen en las prácticas funcionan como sinónimos, son la unión de diferentes disciplinas sin objeto propio, a la vez no son sino una mera mezcla homogénea e indistinta de ver la realidad educativa. Un ejemplo de esto es cómo al estar dentro del aula el maestro se preocupa y se deja envolver por la forma de "transmitir" los contenidos de las áreas correspondientes lo cual se puede evidenciar desde la planificación, selección y ejecución (un ejemplo de ello son las actividades), mientras que la pedagogía es menos perceptible, por lo menos desde las instituciones, los sujetos y por ende desde las prácticas, entonces surgen las preguntas ¿En qué momento se puede decir que hay pedagogía? ¿En qué hechos o materializaciones se puede evidenciar o hacer visible la pedagogía? ¿Cómo diferenciar y relacionar la pedagogía y la didáctica?

La pedagogía ha sido reducida a un simple saber instrumental que establece reglas y procedimientos con los cuales el maestro traduce el discurso del conocimiento en contenidos para la enseñanza. El análisis hecho desde las ciencias de la educación se ha centrado en el exterior de los procesos de conocimiento sobre la enseñanza (Martínez Boom, 2008) 
Es decir, se relacionaría con una forma de asumir la enseñanza, las relaciones con la didáctica y la pedagogía; donde pareciera que por momentos se hablara de lo pedagógico en términos de didáctica; no quiere decir que sea una disciplina menos o más importante sino que tienen puntos de encuentro, complementariedades y diferencias, por lo que se hace importante preguntarse por los distintos saberes del maestro, por cómo funcionan desde su práctica; vale preguntarse por la pedagogía, entendida ésta como una disciplina que tiene un ámbito amplio de objetos, como la educación, la enseñanza, el aprendizaje, entre otros.

Siendo el saber pedagógico, el saber propio del maestro cabe resaltar el carácter reflexivo con el que éste cuenta, siendo parte de la constitución como sujetos y posibilitando a su vez diferentes miradas los objetos ya mencionados, con el fin de dar el lugar que le corresponde al maestro, no solo como técnico de una disciplina, sino que es un sujeto que puede construir sus propias situaciones y trascender a otros campos no solo al aula de clases, y de esta manera darse la oportunidad de pensar que no somos sujetos acabados y que a la vez otros tienen el derecho a serlo. Posiblemente, la pedagogía y la didáctica tengan solapamientos, interacciones y divergencias en su mirada hacia la enseñanza, pero claramente las distinciones que se deban realizarse deben ser fundamentales como maestros en formación, pues muchos de los problemas que aquejan a los maestros es la falta de tiempo, por lo que no se profundizaría en esta problemática como correspondería, trayendo consigo inconvenientes en la constitución como sujetos y de una sociedad, siendo una oportunidad para pensarse como maestros y a la vez construir identidades propias y no impuestas o aceptadas por omisión provenientes de otros. La practica pedagógica cobra relevancia en la medida que su constitución no sólo consecuencias a corto sino a largo plazo.

\section{Sobre la Enseñanza de la Biología}

La noción de práctica pedagógica cobra un sentido profundo para el Licenciado en Biología; pues se trata no sólo de un momento en el actúa como un "docente profesional" sino del espacio académico-vivencial que permite abrir la mirada frente a los saberes y prácticas que circulan sobre la escuela, la enseñanza de la biología y el ejercicio de maestro. Lo anterior, tiene que ver con un modo de asumir al maestro como intelectual y constructor de cultura que no se preocupa sólo por lo que acontece en el aula, sino por lo que le afecta como sujeto de saber. De este modo, más que referirnos al Profesor de biología, hablamos del Licenciado- Maestro de Biología que asume en su quehacer la práctica pedagógica como un punto fundamental, en el que convergen la reflexión de los saberes y prácticas, siendo para el caso, la enseñanza de la biología, la categoría que da lugar a cuestionamientos y posibilidades, de esta manera, la enseñanza toma su dimensión creadora e intelectual, elemento constitutivo del maestro, y no se restringe al espacio de las clases, al facilitar los aprendizajes; sino, que se constituye en palabras de Martínez Boom (2008) en la vía del pensamiento. Se asume entonces, la complejidad de la enseñanza tomándola como un "sustrato" (Riveros, 2004) que posibilita un dialogo y recomposición de los saberes y que a su vez configura a estos dos sujetos.

Desde la enseñanza aparece un interrogante dirigido a las condiciones que el saber biológico y la biología tienen en la escuela, de modo que el acercamiento al ejercicio de la enseñanza de la biología en la práctica pedagógica muestra que ésta no se relaciona únicamente con la pregunta sobre cómo enseñar biología, ni cómo facilitar el aprendizaje de conceptos, teorías y modelos también indaga por el saber que se presume enseñar, el biológico y sobre las distintas formas y 
apropiaciones escolares del mismo. Así la enseñanza de la biología, entendida como la apuesta por el pensamiento, atraviesa no sólo los campos del saber científico, también cruza los campos de orden social, político, ético y estético que permean las prácticas del maestro y de los estudiantes; el lente de la mirada es la pedagogía lo que permite indagar las distintas relaciones que se han construido alrededor de la enseñanza de la biología.

Es así que al interior de la práctica pedagógica se presenta también la posibilidad de pensar y problematizar la enseñanza de la biología a partir de la reflexión como maestros en formación. Recordamos por ejemplo, como lo hizo Riveros (2004) que "la biología no siempre existió y ha sido una construcción histórica que responde a un encuentro de fuerzas que le permitieron pasar por umbral de epistemologización y convertirse en disciplina" (p.75); de manera que la biología no siempre ha sido una disciplina susceptible de ser enseñada.

Esto permite pensar que las construcciones históricas de la biología como disciplina se han enmarcado dentro de lógicas diferentes a las realidades vividas al interior de la escuela. De este modo, la enseñanza de la biología como vehículo que permite pensar el mundo de lo vivo, es uno de los aspectos que se van configurando como experiencia singular en los trayectos de la práctica pedagógica, de manera que cada maestro en formación configura su trayecto, y si bien hay espacios para el encuentro, puntos de convergencia entre los miembros del equipo, se ha buscado hasta el momento no objetivar perfiles de maestro ni de investigación; sino involucrar durante la práctica las diferentes dimensiones del sujeto y dar lugar a los diversos modos de apropiación y subjetivación que pueden darse en el complejo y dinámico proceso de la práctica pedagógica.

Por tanto lo que nos permite la Pedagogía es una reflexión de las prácticas dentro y fuera de las instituciones educativas, permitiendo problematizar el acontecer del maestro, preguntarse por el papel que juega en la institución, en la sociedad y la academia; así mismo dichas reflexiones aunque direccionan por la pedagogía atraviesan la biología puesto que es la disciplina que enseñamos el vehiculo que nos permite brindar una forma de conocer lo vivo.

\section{Consideraciones Finales}

La práctica pedagógica que luego de las líneas precedentes puede ser descrita como un momento para mirarse, para mirar el ejercicio de maestro, para ver las prácticas que configuran los diferentes modos de escuela y de enseñanza; para experimentar el sentirse profesor desde los lentes de la reflexión pedagógica y de la investigación, mostrando cómo es en los trayectos donde se construye la práctica como una experiencia, en tanto generadora de elementos que trascienden la palabra y la acción para entrar en la configuración del maestro como sujeto singular. Así, la evidencia de diferentes tensiones en el escenario escolar entre las dinámicas que "deben ser" y las que "queremos que sean", entre la absorción de la gestión rutinaria y el ejercicio de una enseñanza diferente y posibilitadora; entre las competencias y el conocimiento, entre la vigilancia, el control y la libertad; entre otras; se convierten en elementos que dan lugar a la crisis y con ello a la pregunta. La pregunta, se establece entonces como un modo de leer lo que nos configura, lo que permite unos modos de escuela, de enseñanza, de relación con el conocimiento; mostrándonos que de algún modo la investigación se constituye como una actitud que afecta principalmente al investigador; en este caso a los maestros, una actitud frente a la enseñanza, frente a las disciplinas, frente a las instituciones, frente a los otros, frente a sí mismo y frente al país. Lo que se ha expuesto hasta el momento son sólo algunas reflexiones y preguntas que han surgido al interior de la práctica; aspectos que no se encuentran aislados de otros 
cuestionamientos que son objeto de problematización de las maestras en formación: la evaluación y la configuración de maestros, los discursos de investigación escolar, los saberes pedagógicos que construyen los maestros, las apropiaciones de saber sobre el ambiente y la educación ambiental y el funcionamiento y las creencias en torno a estrategias de enseñanza como las huertas escolares; todos estos objetos de discurso, de política, de saber, prácticas que desde la perspectiva de estos Licenciados en Biología cobran importancia al estar en el ámbito educativo que es visto en este sentido como una conjunción de elementos que permiten construir y transformar la cultura.

Una experiencia académica, política y ética, donde los que aprenden y se construyen no son sólo los estudiantes sino el maestro o "el asesor de práctica" quien es también sujeto de saber, que puede hacer también del ejercicio de enseñanza y "asesoría" una experiencia investigativa de su espacio y de los objetos de análisis que alimentan la línea de investigación; mostrando una vez más que se es maestro desde los trayectos y aconteceres que se trazan en estas experiencias pedagógicas.

\section{Bibliografía}

- COSTA DE ALMEIDA, J; NOVAIS CORDEIRO. La actividad de investigación en Ciencia y Arte. Of the world web site http://www.efdeportes.com/efd119/la-actividad-de-investigacion-enciencia-y-arte.htm. Fecha última revisión: 12 de Octubre de 2008. Fecha último acceso: 21 de Noviembre de 2008.

- FOUCAULT M. 2005. Historia de la Sexualidad, Volumen 2 El uso de los placeres, Siglo XXI Editores. España. 292 p.

- MARTÍNEZ BOOM, A y UNDA BERNAL, M. 1995. Maestro: Sujeto de saber y prácticas de cualificación. Revista Colombiana de Educación. Segundo semestre (31): 102, 103.

- MARTINEZ BOOM, A., 2004. De la escuela expansiva a la escuela competitiva dos modos de modernización en América latina, Anthropos, Barcelona, España. 459 p.

- MARTÍNEZ BOOM, A., 2008 a.Teoría Pedagógica una mirada arqueológica a la pedagogía de 2008 desde http://www. Of the world wb site pedagógica.edu.co/storage/ps/pedysab01_04arti.pdf. Fecha última revisión: 20 de Octubre de 2008. Fecha último acceso 30 de Octubre de 2008.

- MARTÍNEZ BOOM, A. 2008 b. Posdata a la vergüenza. Of the world web http://posdataalaverguenza.blogspot.com/. Fecha última revisión: 28 de Octubre de 2008. Fecha último acceso: 10 de Noviembre de 2008.

- MORA, R. LA INVESTIGACION PEDAGÓGICA, MITO O REALIDAD: UNA REFLEXION SOBRE SU PRACTICA Director del Grupo de Investigación en "Educación, Pedagogía y Cultura en el Caribe colombiano" of the world web site http://unisimonbolivar.edu.co/revistas/aplicaciones/doc/200.pdf. Fecha última revisión 27 octubre 2008. Fecha último acceso: 12 de noviembre de 2008.

- NOGUERA, Carlos. 1991. Una reflexión ética desde el saber pedagógico. Pedagogía y Saberes. (2): 26

- RAMÍREZ, E, A. 1998. La Investigación Pedagógica. Cuadernos de Filosofía Latinoamericana. (7273): 163.

- RIVEROS GAONA, O. L. 2004. La historia de la enseñanza de la biología desde el concepto 'organismo'. Revista Intersticios 1: 15-92.

- SALDARRIAGA O., 2003. Del oficio de Maestro. Prácticas y teorías de la pedagogía moderna en Colombia. Editorial Magisterio, Bogotá. Capítulo 5 El maestro: ¿Pedagogo, Intelectual o Maestro?. 316 p. 
- VALBUENA, E., SIERRA, C., GUTIERREZ, A. Segundo Semestre 2007 Una década de investigación en la facultad de ciencia y tecnología de la Universidad Pedagógica Nacional. TEA № 22. p. 147.

- ZULUAGA, O., ECHEVERRI, A., MARTíNEZ, A., RESTREPO S., QUICENO H. 1999. Educación y Pedagogía: Una diferencia necesaria p.21-40. En: Zuluaga, O; Echeverri, A; Martínez, A; Quiceno, H; Saenz, J; Álvarez, A. Pedagogía y epistemología, Corporativa editorial MAGISTERIO, Bogotá, Colombia, 301 p. 